\title{
Recovery Experience: A Concept for Maintaining Quality of Life and Its Mediating Effect Among Female Nurses in China
}

This article was published in the following Dove Press journal: Psychology Research and Behavior Management

\author{
Fengzhi Yang ${ }^{1, *}$ \\ Jialin Ding ${ }^{1} *$ \\ Ruqing $\mathrm{Ma}^{\mathrm{I}}$ \\ Wenjie Song ${ }^{2}$ \\ Yajing Jia' \\ Jinfeng Zhao (iD) ${ }^{3}$ \\ Xiaoshi Yang (D)
}

'Department of Social Medicine, School of Public Health, China Medical

University, Shenyang, Liaoning Province

I I0I22, People's Republic of China;

${ }^{2}$ Office of Clinical Quality Improvement,

Children's Hospital of Philadelphia,

Philadelphia, PA 19/47, USA; ${ }^{3}$ Faculty of

Medical and Health Sciences, The

University of Auckland, Auckland I I42,

New Zealand

*These authors contributed equally to this work
Correspondence: Xiaoshi Yang

Department of Social Medicine, School of Public Health, China Medical University,

No. 77 Puhe Road, Shenyang North New

Area, Shenyang, Liaoning Province

I 10122, People's Republic of China

Tel +86-18900910796

Fax +862431939406

Email xsyang@cmu.edu.cn
Purpose: Nurses are high-risk groups for job burnout, which affect their quality of life (QOL). Recovery experience, a conceptualization of positive psychological resources, can combat the negative impacts of job burnout on health and QOL. The aim of this study was to examine the mediating effect of recovery experience on the relationship between job burnout and QOL among female nurses in China.

Participants and Methods: QOL information was captured from 1068 female nurses from December 2017 to February 2018 in tertiary hospitals in Shenyang, Liaoning Province of China. A structural equation model was employed to examine the mediating effect of recovery experience on the relationship between job burnout and QOL.

Results: Job burnout had a significant impact on both the mental component summary and the physical component summary of a 36-item Short-Form Health Survey. However, mental component summary scores were significantly lower than physical component summary scores in female nurses. Recovery experience played a mediating role in the relationship between job burnout and QOL.

Conclusion: Job burnout could result in a reduction in QOL among Chinese female nurses. Recovery experience, as a mediating factor, could alleviate the impact of job burnout on QOL. Recovery experience should be strengthened to attenuate job burnout and enhance QOL.

Keywords: job burnout, quality of life, recovery experience, Chinese female nurses

\section{Introduction}

Nursing is an occupation with a high level of job burnout, and nurses are considered to be vulnerable to stress-related diseases that affect their health status and quality of life (QOL). ${ }^{1,2}$ A large number of reports indicate that occupational stress, burnout, high turnover and taking long-term sick leave are common among Chinese nurses. ${ }^{3,4}$ Female nurses are at greater risk due to physical and psychological susceptibility to the adverse effects of burnout. ${ }^{5}$ Numerous studies have demonstrated that most female nurses suffer from physical and psychological health problems that seriously impair their QOL., ${ }^{6,7}$ QOL among nurses is significantly lower than that of the general population and it has become a major public health issue in most developed and developing countries. ${ }^{8}$

Nurses play an important role in the process of health-care service delivery. However, they are exposed to excessive workloads, night shift schedules, a lack of social and family support. ${ }^{7,9,10}$ Nurses always face with an imbalance between 
effort exerted and reward received, and high levels of stress from the needs for continuing education and promotion. $^{11}$ Results from previous studies show that health status among nurses might be related to some personal factors such as age, marital status, education and chronic disease. ${ }^{12,13}$ In addition, work-related relationship conflicts and exposure to the unpredictable work-related risks is incompatible in their working conditions. ${ }^{14}$ They also confront with the embarrassed situations that their physical, mental, emotional, social and even spiritual health are challenged every day. ${ }^{15}$ All these factors add to the burden on nurses, resulting in physical and mental suffering, and ultimately leading to a significant reduction in their QOL.

Job burnout was found to have a strong negative correlation with QOL. ${ }^{16}$ Studies have indicated that job burnout is related to medical malpractice, higher absence, and turnover rates, and it has a negative impact on nurses' QOL and the medical treatment outcomes of the patients. ${ }^{17-19}$ Nurses, under the work-related pressure and facing with high work intensity, are susceptible to a high prevalence of job burnout. $^{20}$ The prevalence of job burnout among Chinese nurses ranged from $32 \%$ to $68.1 \%{ }^{21}$ Most previous studies showed that the more severe the burnout was, the higher the prevalence of physical and mental problems were. $^{22,23}$ Therefore, it is very urgent for the nurses to be strengthened with burnout training to prevent from the occurrence of health problems and improve their QOL. $^{24}$

In order to well understand the responses to workrelated stress and the underlying explanations of recovery experiences, the Conservation of Resources (COR) theory and the Effort-Recovery (E-R) Model were referred to provide a theoretical framework in this study. ${ }^{25-27}$ The COR theory describes psychological stress as the result of a threat or actual loss of resources, or lack of resource gain, ${ }^{28}$ while the E-R model explains how recovery experience can put a halt to the process of resource loss. ${ }^{26}$ Recovery experience is an emotional process characterized by a reluctance to continue with present demands, which is based on E-R model and is a conceptualization of the kind of positive resources that can help maintain well-being in the working environment. ${ }^{26}$ Recovery is defined as the state during which the individual's functioning returns to a pre-stressor level and refers to the need to recuperate and wind down after effort invested in work. ${ }^{29}$ Previous studies indicated that the need for recovery was associated with high levels of burnout and was an important indicator of the prevalence of the health problems. ${ }^{30}$ Recovery experience is a positive psychological factor that can alleviate occupational stress, ${ }^{31}$ reduce job burnout, and improve QOL for nurses. It is an important concept in the context of occupational health and professional wellbeing, and can be defined as the process of improving emotions and relieving stress using psychological detachment, relaxation, mastery experiences, and control. ${ }^{32}$ Hong Fang and others have suggested that recovery experience can be used as a personal resource to reduce the negative impacts of job requirements on professional well-being. ${ }^{33}$ A better recovery experience helps the nurses by relieving stress, reducing emotional exhaustion, promoting higher job satisfaction, improving subjective well-being, reducing job burnout, and ultimately improving QOL. ${ }^{34,35}$

Research on recovery experience is still in its infancy in China and there are few studies on nurses' recovery experience. In particular, the impacts of recovery experience on QOL need further analysis, not just to improve understanding, but also to identify interventions to enhance the recovery experience of female nurses and improve their QOL. It is of great importance for the development of female nurses' QOL, as well as for improving the quality and efficiency of health services and patients' treatment outcomes. With the purpose of relieving the adverse effects of job burnout and enhancing the nurses' health status, a cross-sectional survey was conducted among nurses to explore the relation of job burnout and recovery experience to QOL. The research hypotheses were: (1) Job burnout has a direct negative impact on QOL; (2) Recovery experience has a positive impact on QOL; (3) Job burnout also affects QOL through the mediating path of recovery experience.

\section{Materials and Methods}

\section{Participants and Sampling}

A cross-sectional study with the proportional sampling was conducted from December 2017 to February 2018 in tertiary hospitals in Shenyang, Liaoning Province of China. Two hospitals in each area (east, west, south, and north) of Shenyang were randomly selected. The sample consisted of about 1500 female nurses from 8 hospitals in Shenyang in Northeast China. About 30\% of the nurses were randomly selected in the clinical departments of each hospital. Inclusion criteria were: (1) 18-65 years old; (2) having a Registered Nurse license; (3) having worked for 1 year or longer. Self-administered mobile phone 
questionnaires pertaining to demographic characteristics, job burnout, recovery experience and QOL were sent to the selected nurses. A total of 1068 questionnaires were completed, resulting in a $71.2 \%$ valid response rate.

\section{Ethics Statement}

The informed consent of the participants was obtained before the questionnaire began. Each participant gave electronic consent to the survey after being informed of the aims of the study and contents of the questionnaire. The questionnaire took approximately 20 minutes. The research was conducted in accordance with the Helsinki Declaration as revised in 1989, and the protocol was approved by the Ethics Committee of China Medical University (CMU1210400061).

\section{Measures}

\section{Demographic Characteristics of the Participants}

Demographic characteristics included age, marital status, educational level, monthly income, weekly work hours, night shifts worked and chronic diseases. "Marital status" was categorized as "married or cohabiting" and "others" including unmarried, separated or divorced. "Educational level" was categorized as "junior college or lower" and "bachelor or higher". "Monthly income" was categorized as " $<3000$ RMB" and " $\geq 3000$ RMB". "Weekly work hours" was categorized as " $\leq 40 \mathrm{hrs}$./week" and " $>40$ hrs./week". "Night shift" was determined with the question "Do you work night shift (yes/no)?". "Chronic diseases" was determined with the question "Do you have any chronic diseases (yes/no)?".

\section{Job Burnout}

Job burnout was assessed with the Maslach Burnout Inventory-General Scale (MBI-GS) ${ }^{36}$ The Chinese version of MBI-GS composed of 15 items, which is widely used among the Chinese population, ${ }^{37,38}$ and it has three dimensions: emotional exhaustion (5 items, such as, "I feel used up at the end of the workday"), depersonalization (4 items, such as, "I have become less enthusiastic about my work"), and personal accomplishment (6 items, such as, "I deal very effectively with the problems of my work"). There are seven selected answers for each item: never, rarely (several times per year), sometimes (once a month), often (several times per month), frequently (once a week), always (several times per week) and every day. Respondents scored from 0 to 6 according to how often they had experienced the statement. High scores for depersonalization or emotional exhaustion and low scores for personal achievement indicate high levels of job burnout. The original Cronbach's alpha of the MBI-GS was $0.84 .^{39}$ In this study, the Cronbach's alpha coefficient of the MBI-GS was 0.85 and the validity was 0.91 .

\section{Recovery Experience}

Recovery experience was evaluated using the Recovery Experience Questionnaire developed by Sonnentag and Fritz, which has a total of 16 items with a 5-point Likert scale. ${ }^{32}$ Analysis is conducted in four dimensions: psychological detachment (such as, "I forget about work"), relaxation (such as, "I kick back and relax"), mastery experiences (such as, "I learn new things"), and control (such as, "I feel like I can decide for myself what to do"). There were five answers for each item: never, rarely, sometimes, often, and always. Respondents scored from 1 to 5 according to how often they had experienced the statement, with a higher score indicating better recovery experience. The original Cronbach's alpha of the Recovery Experience Questionnaire was $0.83 .{ }^{31}$ In this study, the Recovery Experience Questionnaire's Cronbach's alpha was 0.90 and the validity was 0.89 .

\section{QOL}

The 36-item Short-Form Health Survey (SF-36) is one of the most commonly used universal QOL scales ${ }^{40}$ with eight dimensions: bodily pain (BP), physical function $(\mathrm{PF})$, general perception of health $(\mathrm{GH})$, role limitation due to physical problems (RP), social functioning (SF), energy and vitality (VT), mental health (MH), and role limitation due to emotional problems (RE). It can be categorized as a mental component summary (MCS) and physical component summary (PCS). RE, SF, MH and VT are categorized as mental components, while PF, RP, BP and $\mathrm{GH}$ are categorized as physical components. There is a summarized question in SF-36: "In general, would you say your health is?". Scores range from 0 to 100 with high scores indicating good QOL. The original Cronbach's alpha of the SF-36 was $0.86 .^{41}$ The QOL Cronbach's alpha was 0.65 and the validity was 0.93 in this study.

\section{Statistical Analysis}

$T$-test and ANOVA were used to evaluate QOL categorical variables. Spearman correlation coefficient was used to test the relationship between job burnout, recovery experience and QOL. Hierarchical multiple regression (HMR) analysis was used to test the incremental variance of the 
independent variables. The dependent variable was the QOL of female nurses. The independent variables were entered in the following steps: 1) demographic characteristics and work-related characteristics of the nurses; 2) job burnout; 3) recovery experience. Blocks of variables entered in later stages were tested for their extra contribution to the equation. ${ }^{33}$ A structural equation model (SEM) was used to examine the mediating effect of recovery experience on the relationship between job burnout and QOL. ${ }^{42}$ The dependent variable was QOL and the independent variable was job burnout, while recovery experience was the mediator. The model met the following criteria: $\chi^{2} / \mathrm{df}<5$, CFI $>0.90$, TLI $>0.90$, GFI $>0.90$, and RMSEA $<0.08$. If the direct path coefficient of job burnout on QOL decreased or disappeared of statistical significance after adding mediator of recovery experience, the mediation effect was confirmed. Bootstrapping strategies were used to test the mediating effect ( $\mathrm{a} * \mathrm{~b}$ product) of recovery experience on the relationship between job burnout and QOL, with the bootstrap estimate based on 5000 samples. A bias-corrected and accelerated 95\% CI (BCa $95 \% \mathrm{CI}$ ) for each $\mathrm{a} * \mathrm{~b}$ product was examined. SPSS 17.0 and Amos 17.0 were used to analyze the data. A two-tailed probability value of less than 0.05 indicated statistical significance.

\section{Results}

\section{Demographic Characteristics of the}

\section{Nurses}

The demographic characteristics of the female nurses surveyed are shown in Table 1. The mean age was 32.8 \pm 8.2 years old. More than two-thirds of the nurses were married or cohabiting $(68.4 \%)$, and most nurses had a bachelor or higher degree $(68.7 \%)$ and with a monthly income of 3000 RMB or more (65.9\%). In this study, the majority of the nurses (71.1\%) worked more than $40 \mathrm{hrs}$./week, $55.5 \%$ of the nurses had night shifts of work, and $17.8 \%$ of the nurses suffered from chronic diseases. As shown in Table 2, there were significant differences in the PCS and MCS scores by marital status, weekly working hours and chronic diseases. In addition, nurses who were more than 30 years old reported lower PCS scores than those aged 30 years old or younger. MCS scores were significantly lower than PCS scores. Married or cohabiting nurses had lower scores for both PCS and MCS than the corresponding groups. Nurses who worked more than 40hrs/week reported significantly lower QOL scores than those who worked less than $40 \mathrm{hrs}$./week. Moreover, the
Table I Demographic Characteristics of Female Nurses

\begin{tabular}{|c|c|c|}
\hline & $N=1068$ & $\%$ \\
\hline \multicolumn{3}{|l|}{ Age } \\
\hline$\leq 30$ & 555 & 52.0 \\
\hline$>30$ & 513 & 48.0 \\
\hline \multicolumn{3}{|l|}{ Marital status } \\
\hline Married or cohabiting & 730 & 68.4 \\
\hline Others & 338 & 31.6 \\
\hline \multicolumn{3}{|l|}{ Educational level } \\
\hline Junior college or lower & 334 & 31.3 \\
\hline Bachelor or higher & 734 & 68.7 \\
\hline \multicolumn{3}{|l|}{ Monthly income } \\
\hline$<3000$ RMB & 364 & 34.1 \\
\hline$\geq 3000$ RMB & 704 & 65.9 \\
\hline \multicolumn{3}{|l|}{ Weekly work hours } \\
\hline$\leq 40 \mathrm{hrs} /$ week & 309 & 28.9 \\
\hline$>40 \mathrm{hrs} /$ week & 759 & 71.1 \\
\hline \multicolumn{3}{|l|}{ Night shift } \\
\hline Yes & 593 & 55.5 \\
\hline No & 475 & 44.5 \\
\hline \multicolumn{3}{|l|}{ Chronic diseases } \\
\hline Yes & 190 & 17.8 \\
\hline No & 878 & 82.2 \\
\hline
\end{tabular}

participants with chronic diseases had lower scores for both PCS and MCS than those without chronic diseases.

\section{Correlations Among Job Burnout, Recovery Experience and QOL}

Correlations between job burnout, recovery experience and QOL are provided in Table 3. QOL was significantly correlated with job burnout and recovery experience. Personal accomplishment, relaxation, mastery experiences and control were positively correlated with PCS and MCS $(P<0.05)$, whereas emotional exhaustion, depersonalization and psychological detachment were significantly negatively correlated with PCS and MCS $(P<0.05)$.

\section{Regression Analysis of Job Burnout, Recovery Experience and QOL}

The results of the HMR models of QOL are shown in Tables 4 and 5 . A total of $41.3 \%$ and $51.4 \%$ of the variance was explained by the final regression model of PCS and MCS, respectively. According to the $\mathrm{R}^{2}$ change, job burnout contributed most to the variance of MCS (35.0\%), followed by the PCS (22.5\%). Chronic diseases, emotional exhaustion, 
Table 2 QOL Scores of the Nurses

\begin{tabular}{|c|c|c|}
\hline & PCS & MCS \\
\hline \multicolumn{3}{|l|}{ Age } \\
\hline$\leq 30$ & $74.62 \pm 17.99 * *$ & $64.28 \pm 18.68$ \\
\hline$>30$ & $71.40 \pm 18.63$ & $62.42 \pm 19.84$ \\
\hline \multicolumn{3}{|l|}{ Marital status } \\
\hline Married or cohabiting & $71.73 \pm 18.37$ & $62.11 \pm 19.19$ \\
\hline Others & $75.96 \pm 18.03^{* *}$ & $66.14 \pm 19.14^{* *}$ \\
\hline \multicolumn{3}{|l|}{ Educational level } \\
\hline Junior college or lower & $74.57 \pm 17.78$ & $64.95 \pm 17.89$ \\
\hline Bachelor or higher & $72.39 \pm 18.59$ & $62.68 \pm 19.82$ \\
\hline \multicolumn{3}{|l|}{ Monthly income } \\
\hline$<3000 \mathrm{RMB}$ & $72.35 \pm 18.53$ & $62.05 \pm 19.03$ \\
\hline$\geq 3000$ RMB & $73.45 \pm 18.28$ & $64.08 \pm 19.35$ \\
\hline \multicolumn{3}{|l|}{ Weekly work hours } \\
\hline$\leq 40 \mathrm{hrs} /$ week & $77.28 \pm 16.46 * *$ & $67.70 \pm 18.08 * *$ \\
\hline$>40 \mathrm{hrs} /$ week & $71.36 \pm 18.82$ & $61.63 \pm 19.46$ \\
\hline \multicolumn{3}{|l|}{ Night shift } \\
\hline Yes & $72.72 \pm 18.05$ & $62.58 \pm 19.32$ \\
\hline No & $73.51 \pm 18.75$ & $64.39 \pm 19.16$ \\
\hline \multicolumn{3}{|l|}{ Chronic diseases } \\
\hline Yes & $58.96 \pm 17.85$ & $51.93 \pm 19.65$ \\
\hline No & $76.12 \pm 17.00 * *$ & $65.87 \pm 18.26 * *$ \\
\hline
\end{tabular}

Note: $* * P<0.01$.

depersonalization, psychological detachment, and relaxation were the strong predictors of PCS. Emotional exhaustion, depersonalization, and psychological detachment were negatively associated with PCS, while relaxation was positively associated with PCS. Emotional exhaustion, depersonalization, and psychological detachment were negatively associated with MCS, while personal accomplishment, relaxation, mastery experiences, and control were positively associated with MCS. Chronic diseases and marital status were also the significant predictors of MCS.
Table 4 The Hierarchical Multiple Regression Models of PCS

\begin{tabular}{|c|c|c|c|}
\hline & $\begin{array}{l}\text { Modell } \\
\text { (B) }\end{array}$ & $\begin{array}{l}\text { Model2 } \\
\text { (B) }\end{array}$ & $\begin{array}{l}\text { Model3 } \\
\text { (B) }\end{array}$ \\
\hline \multicolumn{4}{|l|}{$\begin{array}{l}\text { BLOCK I Demographic } \\
\text { characteristics and work- } \\
\text { related characteristics }\end{array}$} \\
\hline Age & 0.027 & -0.033 & -0.026 \\
\hline $\begin{array}{l}\text { Marital status (Married or } \\
\text { cohabiting vs Others) }\end{array}$ & $-0.088 * *$ & $-0.070^{*}$ & -0.049 \\
\hline $\begin{array}{l}\text { Educational level (Junior } \\
\text { college or lower vs Bachelor or } \\
\text { higher) }\end{array}$ & -0.005 & -0.009 & -0.007 \\
\hline $\begin{array}{l}\text { Monthly income (<3000 RMB } \\
\text { vs } \geq 3000 \text { RMB) }\end{array}$ & $-0.068^{*}$ & -0.044 & -0.041 \\
\hline $\begin{array}{l}\text { Weekly work hours ( } \leq 40 \mathrm{hrs} / \\
\text { week vs }>40 \mathrm{hrs} / \text { week) }\end{array}$ & $0.135 * *$ & $0.050 *$ & 0.032 \\
\hline Night shift (yes vs no) & -0.007 & -0.015 & -0.018 \\
\hline Chronic diseases (yes vs no) & $-0.348 * *$ & $-0.229 * *$ & $-0.225 * *$ \\
\hline \multicolumn{4}{|l|}{ BLOCK 2 Job burnout } \\
\hline Emotional exhaustion & & $-0.330 * *$ & $-0.296 * *$ \\
\hline Depersonalization & & $-0.165 * *$ & $-0.109 * *$ \\
\hline Personal accomplishment & & $0.117^{* *}$ & 0.037 \\
\hline \multicolumn{4}{|l|}{$\begin{array}{l}\text { BLOCK } 3 \text { Recovery } \\
\text { experience }\end{array}$} \\
\hline Psychological detachment & & & $-0.189 * *$ \\
\hline Relaxation & & & $0.124 * *$ \\
\hline Mastery experiences & & & 0.032 \\
\hline Control & & & 0.067 \\
\hline $\mathrm{R}^{2}$ & 0.154 & 0.379 & 0.413 \\
\hline$\Delta R^{2}$ & 0.154 & 0.225 & 0.034 \\
\hline
\end{tabular}

Notes: $* P<0.05 ; * * P<0.01$.

\section{The Mediating Role of Recovery Experience on the Relationship of Job Burnout and QOL} The direct pathway of job burnout to QOL is illustrated in Figure 1. The structural equation model (SEM)

Table 3 The Correlation Among Job Burnout, Recovery Experience and QOL

\begin{tabular}{|c|c|c|c|c|c|c|c|c|c|c|c|}
\hline & Mean & SD & $\mathbf{I}$ & 2 & 3 & 4 & 5 & 6 & 7 & 8 & 9 \\
\hline Physical health & 73.07 & 18.36 & I & & & & & & & & \\
\hline Mental health & 63.39 & 19.26 & $0.765 * *$ & I & & & & & & & \\
\hline Emotional exhaustion & 2.29 & 1.60 & $-0.533^{* *}$ & $-0.604 * *$ & I & & & & & & \\
\hline Depersonalization & 1.63 & 1.44 & $-0.499 *$ & $-0.577 * *$ & $0.763 *$ & I & & & & & \\
\hline Personal accomplishment & 4.28 & 1.54 & $0.186^{* *}$ & $0.283 * *$ & $-0.106 * *$ & $-0.199 * *$ & 1 & & & & \\
\hline Psychological detachment & 7.84 & 3.22 & $-0.184 * *$ & $-0.174 * *$ & $0.089 * *$ & $0.197 * *$ & $-0.213^{* *}$ & 1 & & & \\
\hline Relaxation & 11.70 & 3.73 & $0.291 * *$ & $0.384 * *$ & $-0.309 * *$ & $-0.254 * *$ & $0.179 * *$ & $0.343 * *$ & 1 & & \\
\hline Mastery experiences & 12.16 & 3.49 & $0.277^{* *}$ & $0.382^{* *}$ & $-0.297 * *$ & $-0.296 * *$ & $0.314^{* *}$ & $0.247^{* *}$ & $0.658^{* *}$ & 1 & \\
\hline Control & 12.89 & 3.87 & $0.340 * *$ & $0.443^{* *}$ & $-0.385^{* *}$ & $-0.367 * *$ & $0.315^{* *}$ & $0.202 * *$ & $0.690 * *$ & 0.686 ** & I \\
\hline
\end{tabular}

Notes: $* P<0.05 ; * * P<0.01$. 
Table 5 The Hierarchical Multiple Regression Models of MCS

\begin{tabular}{|c|c|c|c|}
\hline & $\begin{array}{l}\text { Modell } \\
\text { (B) }\end{array}$ & $\begin{array}{l}\text { Model2 } \\
\text { (B) }\end{array}$ & $\begin{array}{l}\text { Model3 } \\
\text { (B) }\end{array}$ \\
\hline \multicolumn{4}{|l|}{$\begin{array}{l}\text { BLOCK I Demographic } \\
\text { characteristics and work- } \\
\text { related characteristics }\end{array}$} \\
\hline Age & $0.07 I^{*}$ & -0.007 & 0.011 \\
\hline $\begin{array}{l}\text { Marital status (Married or } \\
\text { cohabiting vs Others) }\end{array}$ & -0.111 ** & $-0.090 * *$ & $-0.063^{*}$ \\
\hline $\begin{array}{l}\text { Educational level (Junior college } \\
\text { or lower vs Bachelor or higher) }\end{array}$ & 0.002 & -0.003 & 0.001 \\
\hline $\begin{array}{l}\text { Monthly income (<3000 RMB } \\
\text { vs. } \geq 3000 \text { RMB) }\end{array}$ & $-0.073 *$ & -0.041 & -0.033 \\
\hline $\begin{array}{l}\text { Weekly work hours ( } \leq 40 \mathrm{hrs} / \\
\text { week vs }>40 \mathrm{hrs} / \text { week) }\end{array}$ & $0.133 * *$ & 0.030 & 0.012 \\
\hline Night shift (yes vs no) & -0.029 & -0.039 & $-0.047^{*}$ \\
\hline Chronic diseases (yes vs no) & $-0.270 * *$ & $-0.126 * *$ & $-0.118 * *$ \\
\hline \multicolumn{4}{|l|}{ BLOCK 2 Job burnout } \\
\hline Emotional exhaustion & & $-0.386 * *$ & $-0.323^{* *}$ \\
\hline Depersonalization & & $-0.207^{* *}$ & $-0.149 * *$ \\
\hline Personal accomplishment & & $0.199 * *$ & $0.096 * *$ \\
\hline \multicolumn{4}{|l|}{ BLOCK 3 Recovery experience } \\
\hline Psychological detachment & & & $-0.181 * *$ \\
\hline Relaxation & & & $0.160^{* *}$ \\
\hline Mastery experiences & & & $0.074 *$ \\
\hline Control & & & $0.091^{* *}$ \\
\hline $\mathrm{R}^{2}$ & 0.111 & 0.460 & 0.514 \\
\hline$\Delta \mathrm{R}^{2}$ & 0.111 & 0.350 & 0.054 \\
\hline
\end{tabular}

Notes: $* P<0.05 ; * * P<0.01$.

showed the negative association of job burnout with PCS $(\mathrm{c}=-0.94, \quad P<0.01)$ and MCS $(\mathrm{c}=-0.99$, $P<0.01)$. This model had good fit with the data $\left(\chi^{2} / \mathrm{df}\right.$
$<5, P<0.01, \mathrm{GFI}=0.974, \mathrm{AGFI}=0.947, \mathrm{CFI}=0.979$, TLI $=0.964$, and RMSEA $=0.059$ ).

The mediating role of recovery experience on the relationship between job burnout and QOL is illustrated in Figure 2. The path coefficient of job burnout to PCS $\left(c^{\prime}=-0.68, P<0.01\right)$ and MCS $\left(c^{\prime}=-0.67, P<0.01\right)$ was decreased significantly when recovery experience was modeled as a mediator. The bias-corrected and accelerated bootstrap test indicated that recovery experience acted as the mediator between the relationship of job burnout and PCS $(\mathrm{a} * \mathrm{~b}=-0.075$, BCa 95\% CI: $-0.107,-0.048)$ and MCS $(a * b=-0.132$, BCa 95\% CI: $-0.165,-0.103)$. This result confirmed the significant mediating role of recovery experience on the relationship between job burnout and QOL. The model presented in Figure 2 is fully supported by all standard goodness of fit indices $\left(\chi^{2} / \mathrm{df}<5\right.$, RMSEA $=0.058, \mathrm{CFI}=0.969, \mathrm{GFI}=0.963$, AGFI $=0.935$, and $\mathrm{TLI}=0.954)$. Thus, job burnout directly affected QOL in this study, and it also influenced QOL indirectly via the mediating path of recovery experience.

\section{Discussion}

To the best of our knowledge, this study is the first to explore the mediating role of recovery experience in the relationship between job burnout and QOL among Chinese female nurses. This study revealed that job burnout had the strongest negative impact on QOL among the nurses, while recovery experience was a mediator between job burnout and QOL. Recovery experience was a positive capability that could increase QOL for the nurses, which

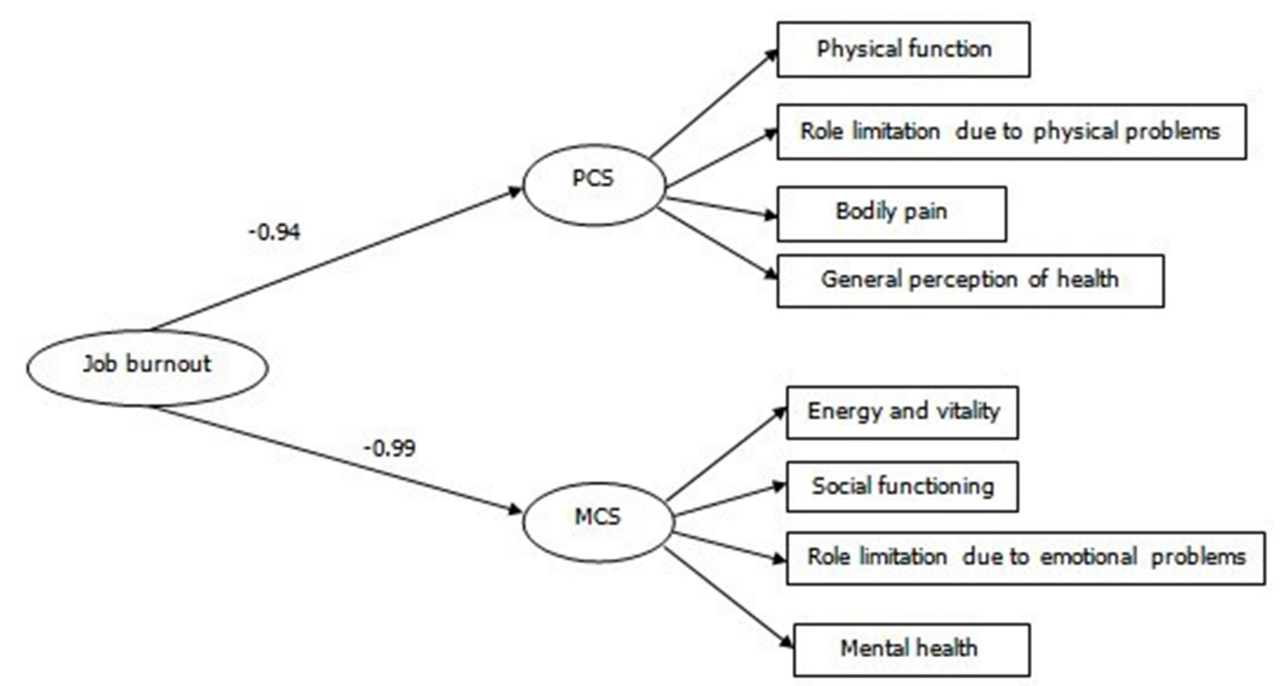

Figure I Standardized solutions for the structural equation model of job burnout and QOL. 


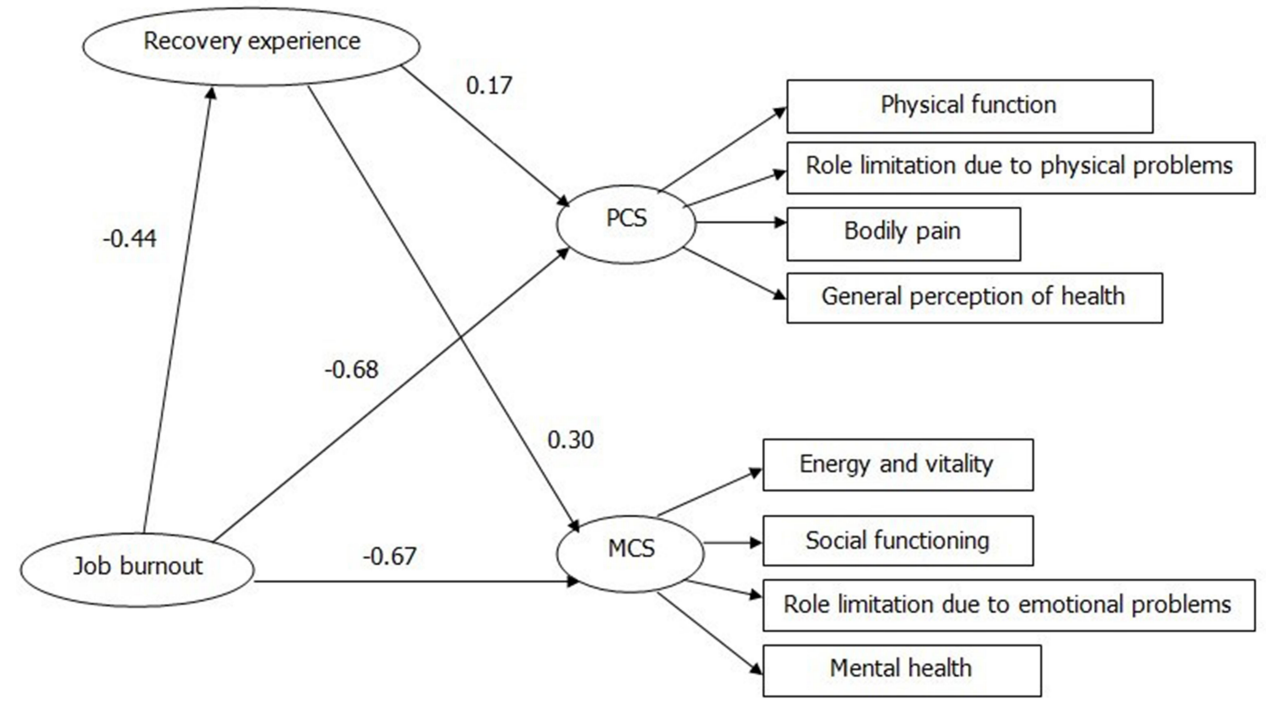

Figure 2 Standardized solutions for the structural equation model of recovery experience, job burnout, and QOL.

was consistent with previous research. ${ }^{43}$ The large number of nurses $(\mathrm{N}=1068)$ participating in the study, the high response rate $(71.2 \%)$, and the fact that Shenyang has a comparable level of health-care services to many urban parts of China, suggest that the results of this study could be applied to other similar populations.

In this study, job burnout contributed most to the variance of both PCS and MCS, accounting for 23.0\% and $36.1 \%$ of the total variance, respectively. Job burnout had the strongest significant impact on QOL among female nurses, which was consistent with the study of Pulcrano. ${ }^{44}$ As the stressful occupational group, nurses are more likely to suffer from job burnout and resulted in the reduction of QOL. ${ }^{45}$ Many studies showed that ongoing exposure to occupational stress can result in job burnout, which can affect physical, psychological and social health. ${ }^{46,47}$ A large number of studies observed that the effects of burnout syndrome might affect nurses' mental health, and there were also some evidence verifying that burnout had bad impact on people's physical health. ${ }^{48,49}$ Job burnout may lead to helplessness, despair, sleep problems, and exhaustion and ultimately affect physical and mental health, which are highly associated with QOL. ${ }^{50}$ Analysis of data in this study showed that nurses' QOL was lower when they reported a higher level of burnout, which is consistent with Suner's study. ${ }^{48}$ The higher the job burnout was, the lower the QOL the nurses experienced, which was in agreement with Khamisa's study that showed nurses had high levels of job burnout and poor general health. ${ }^{51}$ Therefore, the QOL of female nurses should be strengthened through the direct path of managing job burnout by reducing emotional exhaustion and depersonalization, and increasing personal accomplishment training.

Furthermore, job burnout not only had a direct effect on QOL but also had an indirect effect on QOL through the mediating path of recovery experience. This study indicated that there was a significant positive association between recovery experience and QOL among nurses, which was in agreement with previous studies. ${ }^{31,52}$ Recovery experience is a positive psychological resource that can alleviate the negative impacts of emotional exhaustion and depersonalization on QOL. It could promote a sense of personal accomplishment and enhance QOL. Present study also showed that job burnout was negatively correlated with capabilities such as recovery experience and a decreased turnover rate, which could promote health and job satisfaction. ${ }^{53}$ A previous study found that recovery experience was negatively correlated with occupational stress and positively correlated with PCS among nurses. ${ }^{31}$ Practical strategies for developing recovery experience might help the nurses cope adaptively with job burnout. ${ }^{54}$ As a way of coping with work-related stress, recovery experiences have been attracting more researchers' attention. Song and Jeong's studies suggested that recovery experiences as a vital variable could reduce physicians' job burnout and improve employees' psychological well-Being. ${ }^{37,55}$ Results of this study indicated that recovery experience can alleviate job burnout and improve 
QOL for the nurses. The nurses with adequate recovery experience were more likely to combat the negative influence of job burnout on QOL and their health might be enhanced. This study implies that recovery experience played a mediating role in the relationship between job burnout and QOL and become a positive resource for female nurses to improve their QOL. This study highlights the need to develop recovery experience capability-for better management of job burnout in order to improve QOL and well-being.

Previous studies have shown that there is a significant negative correlation between job burnout and recovery experience in oncology medical staff. ${ }^{52}$ High levels of recovery experience might attenuate job burnout, resulting in an improvement in QOL for female nurses. Ta's study showed that recovery experience had a mediating effect between occupational stress and perceptions of the work experience. ${ }^{56}$ Therefore, it is strongly suggested that training for recovery experience should be provided to Chinese nurses to fight against job burnout and improve their QOL and well-being. A 1-year longitudinal study revealed that employees with high stable levels of recovery experiences seemed to suffer least from job burnout, and those with experiences of high levels of mastery and control during offjob time had highest work engagement. ${ }^{57}$ The nurses could refresh themselves after work through relaxing activities such as walking or watching movies to get rid of physical and mental fatigue, consequently, improving their QOL. ${ }^{43}$ Nurses might also engage in the challenging activities in their leisure time - thereby, recovering from stress, gaining energy and improving their health. Mastery experiences can alleviate job burnout and enhance the MCS of female nurses. Our previous study found that recovery experience could improve nurses' mental health, such as depressive symptoms. ${ }^{35}$ Female nurses, choosing specific leisure activities that they prefer, and with a satisfactory sense of control over their lives, might avoid job burnout or recover easier, thus improving their MCS. Interestingly, this study shows that psychological detachment from work can reduce the level of QOL, which is different from previous studies. ${ }^{58}$ This may be due to the fact that female nurses are very sensitive to job burnout, and they not only suffer from a heavy workload but also are responsible for the care and well-being of patients. It is difficult for them to completely separate themselves from their work physically and mentally when they are off duty. ${ }^{59}$ Some studies have indicated that being a workaholic could inhibit psychological detachment during off-work time. ${ }^{60}$ Furthermore, female nurses are able to improve their self- worth and satisfaction at work, which may explain why psychological detachment could reduce QOL in this study. ${ }^{61}$ Therefore, the results of this study may provide suggestions for recovery experience training among the nurses, which could effectively help manage work-related stress and give useful evidence of intervention on the improvement of QOL for nurses.

\section{Limitations}

There are two limitations in this study. On the one hand, this study was a cross-sectional study, thus, causal relationships between research variables were unable to be assessed. Although the hypothesis of this study was based on solid theories and previous research, the results need to be confirmed with a prospective cohort study. On the other hand, this study only included female nurses in hospitals in Liaoning Province. Additionally, it is not clear whether the mediating role of recovery experience on the relationship between job burnout and QOL can be extended to other occupational groups.

\section{Conclusion}

Female nurses suffer more from impaired MCS than from PCS. Job burnout can result in a reduction of QOL for female nurses, whereas recovery experience, as a mediating factor, could alleviate the negative impacts of job burnout on QOL. Thus, it suggests that positive capability strategies aiming at enhancing recovery experience and decreasing job burnout should be developed to enhance QOL for the nurses.

\section{Highlights}

- Mental component summary scores were significantly lower than physical component summary scores in female nurses.

- Job burnout can result in a reduction in the QOL of female nurses.

- Recovery experience, as a mediating factor, can alleviate the impact of job burnout on QOL.

\section{Ethics Approval and Consent to Participate}

All subjects gave their informed consent for inclusion before they participated in the study. The research was conducted in accordance with the Helsinki Declaration as revised in 1989, and the protocol was approved by the Ethics Committee of China Medical University (CMU12 10400061). 


\section{Acknowledgments}

The authors thank Professor Fritz, who authorizes the scale of The Recovery Experience Questionnaire. The authors thank Professor Leiter, who authorizes the scale of the Maslach Burnout Inventory - General Survey (MBI-GS), and we have got a license to use this scale. The authors also thank Professor $\mathrm{Li}$, who authorizes the Chinese version of Maslach Burnout Inventory General Survey (MBI-GS).

\section{Author Contributions}

F.Y. contributed to acquisition and analysis of data, drafting and revision of the manuscript. J. D. contributed to acquisition and interpretation of data and revision of the manuscript. R.M. and Y. $\mathrm{J}$. contributed to acquisition of data and revision of the manuscript. W.S. contributed to revision of the manuscript. Jinfeng Zhao critically reviewed the manuscript and provided English edits. X.Y. was responsible for the conception and design. All authors made substantial contributions to conception and design, acquisition of data, or analysis and interpretation of data; took part in drafting the article or revising it critically for important intellectual content; agreed to submit to the current journal; gave final approval of the version to be published; and agree to be accountable for all aspects of the work.

\section{Funding}

This research did not receive any specific grant from funding agencies in the public, commercial, or not-forprofit sectors.

\section{Disclosure}

The authors report no conflicts of interest in this work.

\section{References}

1. Nowrouzi B, Lightfoot N, Larivière $M$, et al. Occupational stress management and burnout interventions in nursing and their implications for healthy work environments: a literature review. Workplace Health Saf. 2015;63(7):308-315. doi:10.1177/216507 9915576931

2. Bardhan R, Heaton K, Davis M, Chen P, Dickinson DA, Lungu CT. A cross sectional study evaluating psychosocial job stress and health risk in emergency department nurses. Int J Environ Res Public Health. 2019;16(18):3243. doi:10.3390/ijerph16183243

3. Klein M, Wobbe-Ribinski S, Buchholz A, Nienhaus A, Schablon A. Nurse-work instability and incidence of sick leave - results of a prospective study of nurses aged over 40. J Occup Med Toxicol. 2018;13:31. doi:10.1186/s12995-018-0212-y
4. Yang HY, Lv JW, Zhou X, Liu HT, Mi BB. Validation of work pressure and associated factors influencing hospital nurse turnover: a cross-sectional investigation in Shanxi Province, China. BMC Health Serv Res. 2017;17:112. doi:10.1186/s12913-017-2056-z

5. Mudallal RH, Othman WM, Al Hassan NF. Nurses' burnout: the influence of leader empowering behaviors, work conditions, and demographic traits. Inquiry. 2017;54:46958017724944.

6. Ross A, Bevans M, Brooks AT, Gibbons S, Wallen GR. Nurses and health-promoting behaviors: knowledge may not translate into self-care. AORN J. 2017;105:267-275. doi:10.1016/j.aorn.2016.12.018

7. Lambert VA, Lambert CE, Misae I. Workplace stressors, ways of coping and demographic characteristics as predictors of physical and mental health of Japanese hospital nurses. Int J Nurs Stud. 2004;41:85-97. doi:10.1016/S0020-7489(03)00080-4

8. Schluter PJ, Turner C, Huntington AD, Bain CJ, McClure RJ. Work/ life balance and health: the nurses and Midwives e-cohort Study. Int Nurs Rev. 2011;58:28-36. doi:10.1111/j.1466-7657.2010.00849.x

9. Al-Homayan AM, Shamsudin FM, Subramaniam C, Islam R. Impacts of job demands on nurses' performance working in public hospitals. Am J Appl Sci. 2013;10:1050-1060. doi:10.3844/ajassp.2013. 1050.1060

10. Gershon RR, Stone PW, Zeltser M, Faucett J, MacDavitt K, Chou SS. Organizational climate and nurse health outcomes in the United States: a systematic review. Ind Health. 2007;45:622-636. doi: 10.2486/indhealth.45.622

11. Watanabe N, Furukawa TA, Horikoshi M, et al. A mindfulness-based stress management program and treatment with omega- 3 fatty acids to maintain a healthy mental state in hospital nurses (Happy Nurse Project): study protocol for a randomized controlled trial. Trials. 2015;16:36. doi:10.1186/s13063-015-0554-z

12. Molina-Praena J, Ramirez-Baena L, Gómez-Urquiza JL, Cañadas GR, De la Fuente EI, Cañadas-De la Fuente GA. Levels of burnout and risk factors in medical area nurses: a meta-analytic study. Int J Environ Res Public Health. 2018;15(12):2800. doi:10.3390/ ijerph 15122800

13. Cañadas-de la Fuente GA, Ortega E, Ramirez-Baena L, De la Fuentesolana EI, Vargas C, Gómez-Urquiza JL. Gender, marital status, and children as risk factors for burnout in nurses: a meta-analytic study. Int J Environ Res Public Health. 2018;15(10):2102. doi:10.3390/ ijerph15102102

14. Chen Z, Leng J, Pang Y, He Y, Heng F, Tang L. Demographic, occupational, and societal features associated with burnout among medical oncology staff members: cross-sectional results of a Cancer Center in Beijing, China. Psychosoc Oncol. 2019;28(12):2365-2373. doi:10.1002/pon.5230

15. Cruz JP. Quality of life and its influence on clinical competence among nurses: a self-reported study. J Clin Nurs. 2017;26(3-4):388399. doi:10.1111/jocn.13402

16. Meyerson J, Gelkopf M, Eli I, Uziel N. Burnout and professional quality of life among Israeli dentists: the role of sensory processing sensitivity. Int Dent J. 2020;70(1):29-37. doi:10.1111/idj.12523

17. Dall'Ora C, Griffiths P, Ball J, Simon M, Aiken LH. Association of $12 \mathrm{~h}$ shifts and nurses' job satisfaction, burnout and intention to leave: findings from a cross-sectional study of 12 European countries. BMJ Open. 2015;5:e008331. doi:10.1136/bmjopen-2015-008331

18. Adriaenssens J, De Gucht V, Maes S. Determinants and prevalence of burnout in emergency nurses: a systematic review of 25 years of research. Int J Nurs Stud. 2015;52:649-661. doi:10.1016/j.ijnurstu. 2014.11.004

19. Levert T, Lucas M, Ortlepp K. Burnout in psychiatric nurses: contributions of the work environment and a sense of coherence. $S$ Afr J Psychol. 2000;6:36-43. doi:10.1177/008124630003000205

20. Aiken LH, Clarke SP, Sloane DM, Sochalski J, Silber JH. Hospital nurse staffing and patient mortality, nurse burnout, and job dissatisfaction. JAMA. 2002;288:1987-1993. doi:10.1001/jama.288. 16.1987 
21. Yao YC, Zhao S, Gao X, et al. General self-efficacy modifies the effect of stress on burnout in nurses with different personality types. BMC Health Serv Res. 2018;18:667. doi:10.1186/s12913-018-3478-y

22. Naz S, Hashmi AM, Asif A. Burnout and quality of life in nurses of a tertiary care hospital in Pakistan. $J$ Pak Med Assoc. 2016;66:532-536.

23. Colby L, Mareka M, Pillay S, Sallie F. The association between the levels of burnout and quality of life among fourth-year medical students at the University of the Free State. S Afr J Psychiatr. 2018;24:a1101.

24. Ishak W, Nikravesh R, Lederer S, Perry R, Ogunyemi D, Bernstein C. Burnout in medical students: a systematic review. Clin Teach. 2013;10:242-245. doi:10.1111/tct.12014

25. Hobfoll SE. Conservation of resources. A new attempt at conceptualizing stress. Am Psychol. 1989;44(3):513-524. doi:10.1037/0003066X.44.3.513

26. Meijiman TF, Mulder G. Psychological aspects of workload. In: Drenth PJ, Thierry H, De Wolff CJ, editors. A Handbook of Work and Organizational Psychology. Sussex:: Psychology Press; 1998: P5-P34.

27. Zijlstra FR, Cropley M, Rydstedt LW. From recovery to regulation: an attempt to reconceptualize 'recovery from work'. Stress Health. 2014;30(3):244-252. doi:10.1002/smi.2604

28. Hobfoll SE. Social and psychological resources and adaptation. Rev Gen Psychol. 2002;6:307-324. doi:10.1037/1089-2680.6.4.307

29. Sonnentag S, Natter E. Flight attendants' daily recovery from work: is there no place like home? Int J Stress Manage. 2004;11:366-391. doi:10.1037/1072-5245.11.4.366

30. Sluiter JK, van der Beek AJ, Frings-Dressen MH. The influence of work characteristics on the need for recovery and experience health: a study of coach drivers. Ergonomics. 1999;42:573-583. doi:10.1080/ 001401399185487

31. He L, Zhang CL, Yang T, Lan YJ. Relationship between occupational stress, recovery experience, and physiological health of nurses in a municipal grade A tertiary hospital. Zhonghua Lao Dong Wei Sheng Zhi Ye Bing Za Zhi. 2017;35:425-428.

32. Sonnentag S, Fritz C. The recovery experience questionnaire: development and validation of a measure for assessing recuperation and unwinding from work. J Occup Health Psychol. 2007;12:204-221. doi:10.1037/1076-8998.12.3.204

33. Hong F, Zhang RR. The relationship between job requirements and employees' occupational well-being: multiple mediating role of recovery experience. Manage Adm. 2017:333-336.

34. Moreno-Jiménez B, Mayo M, Sanz-Vergel AI, Geurts S, RodríguezMuñoz A, Garrosa E. Effects of work-family conflict on employees' well-being: the moderating role of recovery strategies. J Occup Health Psychol. 2009;14:427-440. doi:10.1037/a0016739

35. Ding J, Gehrman PR, Liu S, et al. Recovery experience as the mediating factor in the relationship between sleep disturbance and depressive symptoms among female nurses in chinese public hospitals: a structural equation modeling analysis. Psychol Res Behav Manag. 2020;13:303-311. doi:10.2147/PRBM.S243864

36. Maslach C, Jackson SE. The measurement of experienced burnout. J Occup Behav. 1981;2:99-113. doi:10.1002/job.4030020205

37. Song Y, Jia Y, Sznajder K, Ding J, Yang X. Recovery experiences mediate the effect of burnout on life satisfaction among Chinese physicians: a structural equation modeling analysis. Int Arch Occup Environ Health. 2020;10.

38. Xu W, Pan Z, Li Z, Lu S, Zhang L. Job burnout among primary healthcare workers in rural China: a multilevel analysis. Int J Environ Res Public Health. 2020;17(3):727. doi:10.3390/ijerph17030727

39. Gil-Monte PR. Validez factorial de la adaptación al español del Maslach Burnout Inventory-General Survey [Factorial validity of the Spanish adaptation of the Maslach Burnout Inventory-General Survey]. Salud Publica Mex. 2002;44(1):33-40. doi:10.1590/S003636342002000100005
40. Yang X, Yao L, Wu H, et al. Quality of life and its related factors in chinese unemployed people: a population-based cross-sectional study. Int J Environ Res Public Health. 2016;13:797. doi:10.3390/ ijerph13080797

41. Lam CL, Tse EY, Gandek B, Fong DY. The SF-36 summary scales were valid, reliable, and equivalent in a Chinese population. J Clin Epidemiol. 2005;58(8):815-822. doi:10.1016/j.jclinepi.2004.12.008

42. Baron RM, Kenny DA. The moderator-mediator variable distinction in social psychological research: conceptual, strategic, and statistical considerations. J Pers Soc Psychol. 1986;51(6):1173-1182. doi:10.1037/0022-3514.51.6.1173

43. Ding J, Jia Y, Zhao J, Yang F, Ma R, Yang X. Optimizing quality of life among Chinese physicians: the positive effects of resilience and recovery experience. Qual Life Res. 2020;29(6):1655-1663. doi:10.1007/s11136-020-02414-8

44. Pulcrano M, Evans SR, Sosin M. Quality of life and burnout rates across surgical specialties. JAMA Surg. 2016;151:970-978. doi:10.1001/jamasurg.2016.1647

45. Wang QQ, Lv WJ, Qian RL, Zhang YH. Job burnout and quality of working life among Chinese nurses: a cross-sectional study. J Nurs Manag. 2019;27(8):1835-1844. doi:10.1111/jonm.12884

46. Singh C, Cross W, Munro I, Jackson D. Occupational stress facing nurse academics-a mixed-methods systematic review. J Clin Nurs. 2020;29(5-6):720-735. doi:10.1111/jocn. 15150

47. Tennant C. Work-related stress and depressive disorders. J Psychosom Res. 2001;51:697-704. doi:10.1016/S0022-3999(01)00255-0

48. Suñer-Soler R, Grau-Martín A, Font-Mayolas S, Gras ME, Bertran C, Sullman MJ. Burnout and quality of life among Spanish healthcare personnel. J Psychiatr Ment Health Nurs. 2013;20(4):305-313. doi:10.1111/j.1365-2850.2012.01897.x

49. Mingote JC, Moreno B, Gálvez M. Burnout and the health of the medical professionals: review and preventive options. Med Clin (Barc). 2004;123:265-270.

50. Känel RV, Nuffel MV, Fuchs WJ. Risk assessment for job burnout with a mobile health web application using questionnaire data: a proof of concept study. Biopsychosoc Med. 2016;10:31. doi:10.1186/s13030-016-0082-4

51. Khamisa N, Peltzer K, Llic D, Oldenburg B. Work related stress, burnout, job satisfaction and general health of nurses: A follow-up study. Int J Nurs Pract. 2016;22:538-545. doi:10.1111/ijn.12455

52. Poulsen MG, Poulsen AA, Khan A, Poulsen EE, Khan SR. Recovery experience and burnout in cancer workers in Queensland. Eur J Oncol Nurs. 2015;19:23-28. doi:10.1016/j.ejon.2014.08.003

53. Khamisa N, Oldenburg B, Peltzer K, Ilic D. Work related stress, burnout, job satisfaction and general health of nurses. Int J Environ Res Public Health. 2015;12(1):652-666. doi:10.3390/ijerph120100652

54. Gluschkoff K, Elovainio M, Kinnunen U, et al. Work stress, poor recovery and burnout in teachers. Occup Med (Lond). 2016;66 (7):564-570. doi:10.1093/occmed/kqw086

55. Jeong JG, Kang SW, Choi SB. Employees' weekend activities and psychological well-being via job stress: a moderated mediation role of recovery experience. Int J Environ Res Public Health. 2020;17 (5):1642. doi:10.3390/ijerph17051642

56. Ta H, Zhang CL, He L, Lan YJ. Analysis of the effect of recovery experience type on regulating the relationship of occupational stress and perceptions of the work experience. Zhonghua Lao Dong Wei Sheng Zhi Ye Bing Za Zhi. 2018;36(4):264-267.

57. Siltaloppi M, Kinnunen U, Feldt T, Tolvanen A. Identifying patterns of recovery experiences and their links to psychological outcomes across one year. Int Arch Occup Environ Health. 2011;84 (8):877-888. doi:10.1007/s00420-011-0672-1

58. Shimazu A, Matsudaira K, Jonge JD, Toaska N, Watanabe K, Takahashi M. Psychological detachment from work during non-work time: linear or curvilinear relations with mental health and work engagement? Ind Health. 2016;54:282-292. doi:10.2486/ indhealth.2015-0097 
59. Sonnentag S, Bayer UV. Switching off mentally: predictors and consequences of psychological detachment from work during off-job time. J Occup Health Psychol. 2005;10:393-414. doi:10.1037/1076-8998.10.4.393

60. Shimazu A, Jonge JD, Kubota K, Kawakami N. Psychological detachment from work during off-job time: predictive role of work and non-work factors in Japanese employees. Ind Health. 2014;52:141-146. doi:10.2486/indhealth.2013-0210
61. Badr H, Herbert K, Reckson B, Rainey H, Sallam A, Gupta V. Unmet needs and relationship challenges of head and neck cancer patients and their spouses. J Psychosoc Oncol. 2016;34:336-346. doi:10.1080/07347332.2016.1195901

\section{Publish your work in this journal}

Psychology Research and Behavior Management is an international, peer-reviewed, open access journal focusing on the science of psychology and its application in behavior management to develop improved outcomes in the clinical, educational, sports and business arenas. Specific topics covered in the journal include: Neuroscience, memory and decision making; Behavior modification and management; Clinical applications; Business and sports performance management; Social and developmental studies; Animal studies. The manuscript management system is completely online and includes a very quick and fair peer-review system, which is all easy to use. Visit http://www. dovepress.com/testimonials.php to read real quotes from published authors. 